\title{
PEMETAAN RANTAI PASOK DAN ANALISIS NILAI TAMBAH KOMODITAS JAGUNG DI KABUPATEN TANAH LAUT
}

\section{SUPPLY CHAIN MAPPING AND ADDED VALUE ANALYSIS OF CORN COMMODITIES IN TANAH LAUT REGENCY}

\author{
R. Rizki Amalia* , Nina Hairiyah, Nuryati \\ Program Studi Agroindustri Politeknik Negeri Tanah Laut \\ Jl. A. Yani Km. 6 Desa Panggung Kecamatan Pelaihari Kabupaten Tanah Laut \\ *Email korespondensi: ra.amalia.rizki@ politala.ac.id
}

Diterima 06-10-2020, diperbaiki 03-11-2020, disetujui 13-11-2020

\begin{abstract}
Kabupaten Tanah Laut is one of the districts in South Kalimantan Province which has the largest of corn production compared to other districts. Based on data from the Office of Horticultural Food Crops and Plantation of Tanah Laut Regency, it was found that the production of corn commodities from 2017 to 2019 increased. This happens because the demand for corn commodities continues to increase every year. In addition, in Tanah Laut Regency, two large animal feed companies have been established that require corn as the main raw material. The magnitude of this potential makes it necessary to identify entities through supply chain mapping so that the added value of each entity can be determined. The purpose of this research was to map the supply chain and analyze the added value of corn commodity supply chain in Tanah Laut Regency. The research method used in analyzing the supply chain is descriptive analysis using purposive sampling and snowball sampling to obtain in-depth and objective information. Meanwhile, value added analysis uses the Hayami method.The results showed that there were three supply chain entities to reach consumers, namely farmers, small collectors, and large collectors. Meanwhile, the results of the analysis of the added value of each entity obtained the highest value, namely the large collectors with a value added ratio of $87 \%$ of $R p$. 783,840.00, small collectors with a ratio of $86.4 \%$ of $R p$. 699,840.00 and farmer entities of 86.13\% with a value of Rp. 671,840.00. This is because the treatment of corn commodities in each entity is different.
\end{abstract}

Keywords: Added value, supply chain mapping, corn commodities

\begin{abstract}
ABSTRAK
Kabupaten Tanah Laut merupakan salah satu Kabupaten yang berada di Provinsi Kalimantan Selatan yang memiliki produksi jagung terbesar dibandingkan Kabupaten Lainnya. Berdasarkan data Dinas Tanaman Pangan Hortikultura dan Perkebunan Kabupaten Tanah Laut diperoleh bahwa produksi komoditas jagung dari tahun 2017 sampai dengan tahun 2019 meningkat. Hal ini terjadi karena permintaan komoditas jagung terus meningkat setiap tahun. Selain itu, di Kabupaten Tanah Laut telah berdiri dua perusahaan besar pakan ternak yang membutuhkan bahan baku utama jagung. Besarnya potensi tersebut membuat perlunya dilakukan identifikasi entitas melalui pemetaan rantai pasok sehingga nilai tambah pada setiap entitas dapat diketahui besarannya. Tujuan dari penelitian ini adalah untuk memetakan rantai pasok dan menganalisis nilai tambah rantai pasok komoditas jagung di Kabupaten Tanah Laut. Metode penelitian yang digunakan dalam menganalisis rantai pasok adalah analisis deskriptif menggunakan puposive sampling dan snowball sampling untuk memperoleh informasi secara mendalam dan obyektif. Sedangkan analisis nilai tambah menggunakan metode
\end{abstract}


Hayami. Hasil penelitian menunjukan bahwa terdapat tiga entitas rantai pasok untuk sampai ke konsumen yaitu yaitu petani, pengumpul kecil, dan pengumpul besar. Sedangkan hasil analisis nilai tambah setiap entitas diperoleh nilai tertinggi yaitu pada pengumpul besar dengan rasio nilai tambah 87\% sebesar Rp. 783.840,00, pengumpul kecil dengan rasio 86, 4\% sebesar Rp. 699.840,00dan entitas petani sebesar 86,13\% dengan nilai Rp 671.840,00. Sedangkan tingkat keuntungan yang diperoleh entitas petani sebesar $67,82 \%$, pengumpul kecil sebesar $68,76 \%$, dan pengumpul besar sebesar $71,22 \%$. Hal ini karena perlakuan pada komoditas jagung pada setiap entitas berbeda.

Kata Kunci: Komoditas jagung, nilai tambah, pemetaan rantai pasok

\section{PENDAHULUAN}

Jagung merupakan komoditas pangan kedua setelah padi dan dapat ditemukan di berbagai pelosok daerah Indonesia seperti di Provinsi Kalimantan Selatan. Penghasil komoditas jagung terbesar lebih dari $50 \%$ dari seluruh Provinsi Kalimantan Selatan berada di Kabupaten Tanah Laut. Selain itu, terdapat dua perusahaan besar yang bergerak dalam pengolahan pakan ternak dengan menggunakan bahan baku utama jagung. Berdasarkan Data Dari Dinas Tanaman Pangan Hortikultura dan Perkebunan Kabupaten Tanah Laut, pada tahun 2017 produksi jagung di Kalimantan Selatan mencapai 152.032 ton. Sedangkan pada tahun 2018 dan 2019 terus mengalami peningkatan produksi yaitu berturut turut sebesar 212.903 ton dan 216.920 ton. Hal ini terjadi karena banyaknya permintaan bahan baku jagung dari perusahaan untuk pembuatan pakan ternak.

Petani biasanya menjual komoditas ke pelaku agroindustri seperti pemasok, pengumpul ataupun konsumen. Hubungan antara setiap pelaku agroindustri ini akan membentuk rantai pasok. Sistem rantai pasok akan berjalan lancar apabila adanya kepastian jumlah pasokan bahan baku dan jumlah permintaan komoditas jagung. Rantai pasok merupakan salah satu cara pendekatan yang digunakan untuk mencapai suatu konsep atau mekanisme untuk meningkatkan produktivitas dalam rantai pasok melalui optimalisasi waktu, lokasi dan aliran kuantitas bahan dengan sistem terkoordinasi yang terdiri dari organisasi, informasi, aktivitas dan sumber daya manusia yang terlihat secara bersama- sama memindahkan suatu produk atau jasa dari pemasok kepada pelanggan.

Permintaan jagung akan terus meningkat dari tahun ke tahun sejalan dengan peningkatan dan kemajuan industri pakan ternak sehingga perlu adanya upaya peningkatan produksi komoditas jagung melalui sumber daya manusia, sumber daya alam, ketersediaan lahan, dan teknologi yang digunakan. Jagung yang khusus dijadikan sebagai pakan ternak biasanya dikeringkan terlebih dahulu agar harganya lebih tinggi dibandingkan jagung yang memiliki kadar air yang tinggi. Hal ini akan memberikan nilai tambah yang menyebabkan petani meningkatkan produksi dan dapat meningkatkan pendapatan petani (Noviantari, 2015). Konsep nilai tambah adalah suatu perubahan nilai yang terjadi karena adanya perlakuan terhadap suatu input pada suatu proses produksi. Arus peningkatan nilai tambah komoditas pertanian terjadi di setiap mata rantai pasok dari hulu ke hilir yang berawal dari petani dan berakhir pada konsumen. Nilai tambah pada setiap entitas rantai pasok berbeda-beda tergantung dari input dan perlakuan oleh setiap anggota rantai pasok tersebut (Marimin dan Slamet, 2010). Pemetaan rantai pasok komoditas jagung di Kabupaten Tanah Laut belum teridentifikasi dengan jelas sehingga nilai tambah pada setiap entitas belum diketahui besarannya. Berdasarkan hal tersebut, maka perlu dilakukan perancangan konsep dengan menggunakan pola pemetaan rantai pasok yang diharapkan dapat menentukan pola aliran rantai pasok dan nilai tambah komoditas jagung pada setiap entitas di Kabupaten Tanah Laut 


\section{METODE}

Penelitian dilakukan pada setiap entitas rantai pasok komoditas jagung di Kabupaten Tanah Laut Propinsi Kalimantan Selatan. Pengumpulan data berupa data primer yang bersumber dari setiap entitas yang berhubungan dengan rantai pasok komoditas jagung. Sedangkan data sekunder bersumber dari Dinas Pertanian, Badan Pusat Statistik, internet serta berbagai literatur yang berkaitan dengan tema penelitian. Data primer yang diperlukan adalah data kualitatif dan kuantitatif mengenai pelaku/ entitas pada struktur rantai pasok, nilai tambah setiap entitas pada rantai pasok. Data primer ini diperoleh dengan cara melakukan wawancara kepada berbagai entitas rantai pasok berdasarkan pertanyaan yang sudah direncanakan agar hasil wawancara sesuai dengan kebutuhan penelitian. Metode pengumpulan data dengan cara melakukan penelusuran rantai pasok yang dimulai dari tingkat petani sampai ke konsumen. Sampel dipilih secara purposive dari tiap entitas petani dengan pertimbangan kemudahan memperoleh informasi. Petani yang dipilih adalah petani yang direkomendasikan oleh Dinas Hortikultura Tanaman Pangan dan Perkebunan di setiap kecamatan. Penelusuran rantai pasok berikutnya ditentukan dengan teknik snowball sampling dimana entitas lainnya ditentukan berdasarkan keterangan dari pihak petani yang berasal dari lokasi penelitian minimal 5 petani sehingga diperoleh informasi mengenai entitas peta rantai pasok komoditas jagung di Kabupaten Tanah Laut. Analisis rantai pasok ini mengacu pada penelitian Amalia dkk. (2017) yaitu menggunakan analisis deskriptif dimana metode ini digunakan dengan tujuan memperoleh gambaran secara mendalam dan obyektif mengenai objek penelitian. Sedangkan analisis nilai tambah yang digunakan pada kajian rantai pasok ini adalah metode Hayami (Tabel 1). Analisis ini digunakan berdasarkan keunggulan metode Hayami untuk mengetahui besarnya pendapatan yang diperoleh oleh setiap anggota rantai pasok, yang terdiri atas tenaga kerja, modal, dan manajemen yang diusahakannya.

Nilai Tambah $=f\{K, B, T, U, H, h$, L \} dimana :

$$
\begin{aligned}
& \mathrm{K}=\text { Kapasitas produksi } \\
& \mathrm{B}=\text { Bahan baku yang digunakan } \\
& \mathrm{T}=\text { Tenaga kerja yang digunakan } \\
& \mathrm{U}=\text { Upah tenaga kerja } \\
& \mathrm{H}=\text { Harga output } \\
& \mathrm{h}=\text { Harga bahan baku } \\
& \mathrm{L}=\text { Nilai input lain (nilai dan semua } \\
& \text { korbanan yang terjadi selama proses } \\
& \text { perlakuan untuk menambah nilai) }
\end{aligned}
$$

\section{HASIL DAN PEMBAHASAN}

\section{Pemetaan Rantai Pasok}

Rantai pasok komoditas pertanian sedikit berbeda dengan rantai pasok non pertanian. Hal ini karena sifat komoditas pertanian mudah rusak, proses penanaman sampai proses pemanenan tergantung terhadap iklim dan musim, adanya variasi ukuran dan bentuk hasil panen sehingga faktor tersebut harus dipertimbangkan dalam rantai pasok komoditas pertanian untuk mendapatkan sistem rantai pasok yang komprehensif, efektif, efisien, dan berkelanjutan (Furqon, 2014). Berdasarkan hasil penelitian diperoleh pemetaan rantai pasok komoditas jagung di Kabupaten Tanah Laut seperti yang terlihat pada Gambar 1. 
Tabel 1. Perhitungan Analisis Nilai Tambah Metode Hayami

\begin{tabular}{|c|c|c|}
\hline No & Variabel & Nilai \\
\hline \multicolumn{3}{|c|}{ Output, input dan harga } \\
\hline 1 & Output $(\mathrm{kg})$ & (1) \\
\hline 2 & Bahan baku (kg) & $(2)$ \\
\hline 3 & Tenaga Kerja Langsung & (3) \\
\hline 4 & Faktor Konversi & $(4)=(1) /(2)$ \\
\hline 5 & Koefisien Tenaga Kerja Langsung (HOK/kg) & $(5)=(3) /(2)$ \\
\hline 6 & Harga output (Rp/kg) & (6) \\
\hline 7 & UpahTenaga Kerja Langsung (Rp/HOK) & $(7)$ \\
\hline \multicolumn{3}{|c|}{ Penerimaan dan Keuntungan } \\
\hline 8 & Harga bahan baku $(\mathrm{Rp} / \mathrm{kg})$ & $(8)$ \\
\hline 9 & Harga input lain $(\mathrm{Rp} / \mathrm{kg})$ & $(9)$ \\
\hline 10 & Nilai output (Rp/kg) & $(10)=(4) \times(6)$ \\
\hline \multirow[t]{2}{*}{11} & a. Nilai tambah $(\mathrm{Rp} / \mathrm{kg})$ & $(11 a)=(10)-(8)-(9)$ \\
\hline & b. Rasio nilai tambah $(\%)$ & $(11 b)=(11 a) /(10) \times 100 \%$ \\
\hline \multirow[t]{2}{*}{12} & a. Pendapatan tenaga kerja langsung $(\mathrm{Rp} / \mathrm{kg})$ & $(12 \mathrm{a})=(5) \times(7)$ \\
\hline & b. Pangsa tenaga kerja langsung (\%) & $(12 b)=(12 a) /(11 a) \times 100 \%$ \\
\hline \multirow[t]{2}{*}{13} & a. Keuntungan $(\mathrm{Rp} / \mathrm{kg})$ & $(13 a)=(11 a)-(12 a)$ \\
\hline & b. Tingkat keuntungan $(\%)$ & $(13 b)=(13 a) /(10) \times 100 \%$ \\
\hline \multicolumn{3}{|c|}{ Balas Jasa Pemilik Faktor Produksi } \\
\hline \multirow[t]{4}{*}{14} & Marjin $(\mathrm{Rp} / \mathrm{kg})$ & $(14)=(10)-(8)$ \\
\hline & a. Pendapatan tenaga kerja langsung $(\%)$ & $(14 a)=(12 a) /(14) \times 100 \%$ \\
\hline & b. Sumbangan input lain (\%) & $(14 b)=(9) /(14) \times 100 \%$ \\
\hline & c. Keuntungan perusahaan $(\%)$ & $(14 c)=(13 a) /(14) \times 100 \%$ \\
\hline
\end{tabular}

Sumber: Marimin dan Maghfiroh (2010)

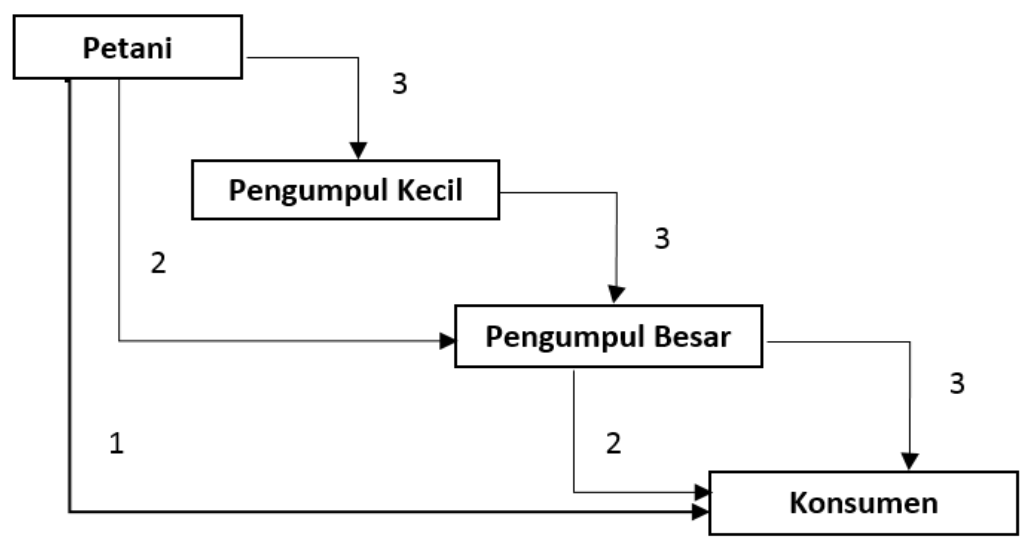

Gambar 1. Peta rantai pasok komoditas jagung di Kabupaten Tanah Laut

Berdasarkan Gambar 1 terdapat 3 entitas pada rantai pasok komoditas jagung di Kabupaten Tanah Laut yaitu petani, pengumpul kecil dan pengumpul besar. Petani jagung merupakan penyedia bahan baku berupa jagung. Hasil panen komoditas jagung ini ada yang dijual ke kelompok tani, pengumpul kecil, pengumpul besar dan juga langsung ke konsumen. Pada proses penjualannya petani biasanya langsung menjual komoditas jagung ini tanpa mensortir terlebih dahulu. Petani jagung di Kabupaten Tanah Laut tersebar di hampir seluruh kecamatan yaitu Kecamatan Batu Ampar, Panyipatan, Pelaihari, Jorong, Bajuin, Takisung, Kurau, Bati-bati, 
Tambang Ulang dan Kintap. Pengumpul kecil merupakan pemasok yang membeli jagung ke beberapa petani. Pengumpul kecil ini biasanya pemasok perorangan dan juga ada yg berkelompok seperti kelompok tani jagung yang aktivitasnya tidak hanya mengikuti Program Pemerintah tetapi juga ikut melakukan penjualan jagung ke pengumpul besar. Pengumpul kecil biasanya melakukan penyortiran bahan baku dengan memisahkan produk yang kualitasnya baik dengan yang rusak kemudian bahan baku tersebut dijual ke pengumpul besar. Harga bahan baku yang sudah dipisahkan berbeda tergantung dari ukuran dan bentuk fisik jagung. Pengumpul besar merupakan pemasok yang mengambil bahan baku baik dari petani dan pengumpul kecil. Semua bahan baku tersebut kemudian disortir kembali untuk memisahkan bahan baku yang kualitasnya baik dan tidak layak. Bahan baku yang kualitasnya baik dilakukan proses pengeringan agar kadar air jagung rendah sehingga sesuai dengan standar mutu yang diinginkan konsumen sesuai dengan SNI 01-4483-1998 yaitu maksimum $14 \%$. Jika bahan baku lebih dari $14 \%$ biasanya harga bahan baku menjadi lebih murah di konsumen. Konsumen merupakan perusahaan pakan ternak yang ada di Kabupaten Tanah Laut. Konsumen mendapatkan bahan baku jagung tidak hanya dari pengumpul besar tetapi melalui beberapa entitas rantai pasok seperti Gambar 1 diantaranya:

1. Peta aliran rantai pasok 1 merupakan aliran rantai pasok yang memiliki lintasan paling pendek yaitu dari petani $\rightarrow$ konsumen. Pada pola aliran ini petani merupakan penyedia bahan baku sekaligus biasanya sebagai pengumpul besar sehingga bahan baku bisa langsung dijual ke konsumen dalam jumlah besar. Hubungan antara petani dan konsumen memiliki hubungan kerjasama melalui sistem kontrak sebagai pemasok bahan baku jagung. Hal ini dilakukan untuk melancarkan proses produksi pakan ternak. Menurut Saputra dkk. (2017) hubungan antara petani dan konsumen atau produsen dan perusahaan adalah adanya hubungan kemitraan atau kerjasama melalui kesepakatan kontrak dimana komitmen harus saling memuaskan dan menumbuhkan saling ketergantungan. Rantai pasok yang paling terpendek menguntungkan bagi petani dibandingkan dengan rantai pasok yang panjang. Bubun dkk. (2018) menyatakan bahwa manajemen rantai pasok yang baik adalah dimana rantai pasok tersebut dapat memangkas rangka rantai pasok, sehingga petani dapat langsung memiliki akses terhadap konsumen dan menjual produknya dengan harga yang relatif tinggi. Persentase petani yang menjual hasil jagung langsung ke konsumen sangat sedikit yaitu berkisar $7 \%$. Hal ini karena petani ini juga sebagai pengumpul besar yang harus memiliki modal besar untuk mengeringkan jagung agar sesuai dengan kesepakatan kerjasama dengan konsumen.

2. Peta aliran rantai pasok 2 yaitu petani $\rightarrow$ pengumpul besar $\rightarrow$ konsumen. Pada lintasan ini pengumpul besar mendapatkan pemasokan bahan baku dari beberapa petani yang selanjutnya disortir dan dikeringkan terlebih dahulu sehingga kadar airnya rendah untuk langsung dijual ke konsumen. Menurut Firmansyah (2009) kadar air biji jagung yang yang beredar di masyarakat khususnya petani jagung rata-rata masih memiliki kadar air yang tinggi yaitu sekitar 25-35\% sehingga tidak dapat disimpan dalam waktu yang cukup lama, sementara dalam kebutuhan industri kadar air biji jagung maksimal $14 \%$. Proses pengeringan merupakan satusatunya cara untuk menurunkan kadar air jagung hingga mencapai standar, sehingga pengeringan menjadi bagian yang terpenting dalam memproduksi jagung berkualitas (Arsyad, 2018). Selain itu, pengumpul besar biasanya memberikan informasi mengenai harga dan permintaan bahan baku serta modal kepada petani baik berupa uang tunai 
ataupun sarana yang dimanfaatkan untuk proses usaha tani. Hal ini sesuai dengan Husnarti (2017) yang menjelaskan bahwa pengumpul berperan dalam pemberian modal pada petani dan berperan juga dalam memberikan informasi tentang harga dan permintaan produk pertanian. Persentase petani yang menjual produk jagung melalui pengumpul besar sekitar 29\%. Biasanya petani dalam lintasan rantai pasok ini memiliki lahan yang luas sehingga pengumpul besar memberikan pinjaman modal dengan kesepakatan penjualan jagung harus melalui pengumpul besar tersebut.

3. Peta aliran rantai pasok 3 ini merupakan aliran rantai pasok terpanjang dibandingkan lintasan yang lain dimana dimulai dari petani $\rightarrow$ pengumpul kecil $\rightarrow$ pengumpul besar $\rightarrow$ konsumen. Pengumpul besar mendapatkan pemasokan bahan baku jagung dari beberapa petani, beberapa pengumpul kecil termasuk juga kelompok tani. Harga jual jagung dari petani ke pengumpul kecil dan kelompok tani yaitu Rp. 2.600,-/ kg. Sedangkan pengumpul kecil/ kelompok tani menjual jagung ke pengumpul besar seharga Rp. $2.700,-/ \mathrm{kg}$. Sedangkan pengumpul besar menjual jagung ke konsumen sebesar Rp. 3.000,-/kg. Walaupun aliran rantai pasok ini panjang, namun ada sebagian besar petani menjual produknya ke pengumpul kecil kelompok tani sehingga hasil keuntungan yang diperoleh kelompok tani akan dibagikan juga ke petani-petani yang masuk dalam anggota kelompok tani. Menurut Djiwandi (1994) dalam Nuryanti dan Swastika (2011), kelompok tani merupakan organisasi yang dapat dikatakan berfungsi penting sebagai wadah pembinaan petani yang tergabung di dalamnya, sehingga dapat memperlancar pembangunan pertanian. Kelompok tani yang aktivitasnya juga sebagai pengumpul kecil berada di Kecamatan Panyipatan. Petani yang menggunakan lintasan ini paling banyak yaitu sekitar $64 \%$ karena biasanya petani yang menggunakan lintasan ini memiliki lahan pertanian yang sempit, kekurangan modal usaha, lebih mudah menjual produk karena biasanya lokasi pengumpul kecil berada dekat dengan petani.

Marimin dan Maghfiroh (2010) menyatakan lintasan yang paling efektif adalah lintasan yang paling pendek yaitu lintasan pertama dari konsumen langsung ke produsen karena bahan baku yang dihasilkan oleh produsen langsung ke konsumen tanpa ada perantara sehingga keuntungan yang diperoleh lebih besar. Namun sebagian besar petani biasanya tetap melalui lintasan yang lebih panjang karena selain adanya kontrak dengan pengumpul, hasil panen juga langsung dibawa oleh pengumpul sehingga hasil panen tidak rusak ketika proses penyimpanan. Menurut Kambey dkk. (2016), penjualan melalui pengumpul lebih menguntungkan dibandingkan dijual sendiri ke konsumen karena pengumpul biasanya membeli komoditas jagung per lahan milik petani.

\section{Nilai Tambah}

Konsep nilai tambah terjadi karena adanya perlakuan input pada komoditas. Perlakuan ini dapat berupa proses pengolahan, pengemasan, penyimpanan, distribusi dan lain lain dalam suatu proses produksi yang menyebabkan terjadinya nilai tambah pada komoditas tersebut (Marimin dan Maghfiroh, 2010). Setiap entitas baik petani, pengumpul kecil dan pengumpul besar memiliki nilai tambah yang berbeda sesuai dengan perlakuan terhadap input komoditas jagung. Perbedaan nilai tambah komoditas jagung dapat dilihat pada Tabel 2. 
Tabel 2. Analisis Nilai Tambah Pada Setiap Entitas Rantai Pasok Komoditas Jagung

\begin{tabular}{|c|c|c|c|c|}
\hline \multirow{2}{*}{ No } & \multirow{2}{*}{ Variabel } & \multicolumn{3}{|c|}{ Nilai } \\
\hline & & Petani & $\begin{array}{l}\text { Pengumpul } \\
\text { Kecil }\end{array}$ & Pengumpul Besar \\
\hline \multicolumn{5}{|c|}{ Output, Input dan Harga } \\
\hline 1 & Output (kg) & 6000 & 6000 & 6000 \\
\hline 2 & Input bahan baku (kg) & 20 & 20 & 20 \\
\hline 3 & Input tenaga kerja (HOK) & 6 & 6 & 6 \\
\hline 4 & $\begin{array}{l}\text { Faktor konversi ( } \mathrm{Kg} \\
\text { output/kg bahan baku) }\end{array}$ & 300 & 300 & 300 \\
\hline 5 & $\begin{array}{l}\text { Koefisien tenaga kerja } \\
(\mathrm{HOK} / \mathrm{Kg})\end{array}$ & 0.3 & 0.3 & 0.3 \\
\hline 6 & Harga output (IDR/Kg) & Rp. $2.600,00$ & Rp. $2.700,00$ & Rp. $3.000,00$ \\
\hline 7 & $\begin{array}{l}\text { Rata-Rata upah tenaga kerja } \\
\text { (IDR/HOK/Kg) }\end{array}$ & Rp. $476.147,00$ & Rp. $476.147,00$ & Rp. 476.147 \\
\hline \multicolumn{5}{|c|}{ Pendapatan dan Keuntungan } \\
\hline 8 & Harga bahan baku (Rp/Kg) & Rp. $52.000,00$ & Rp. $54.000,00$ & Rp. $60.000,00$ \\
\hline 9 & $\begin{array}{l}\text { Sumbangan input lain } \\
(\mathrm{Rp} / \mathrm{Kg})\end{array}$ & Rp. 56.160,00 & Rp. 56.160,00 & Rp. $56.160,00$ \\
\hline 10 & Nilai output $(\mathrm{Rp} / \mathrm{Kg})$ & Rp. $780.000,00$ & Rp. $810.000,00$ & Rp. $900.000,00$ \\
\hline 11.a & Nilai tambah $(\mathrm{Rp} / \mathrm{Kg})$ & Rp. $671.840,00$ & Rp. 699.840,00 & Rp. $783.840,00$ \\
\hline $11 . \mathrm{b}$ & Rasio Nilai tambah (\%) & 86,13 & 86,4 & 87 \\
\hline 12.a & $\begin{array}{l}\text { Imbalan tenaga kerja } \\
(\mathrm{Rp} / \mathrm{Kg})\end{array}$ & Rp. $142.844,00$ & Rp. $142.844,00$ & Rp. $142.844,00$ \\
\hline $12 . \mathrm{b}$ & Bagian tenaga kerja (\%) & 21,26 & 20,41 & 18,22 \\
\hline $13 . \mathrm{a}$ & Keuntungan (Rp/Kg) & Rp. 528.996,00 & Rp. 556.996,00 & Rp. $640.996,00$ \\
\hline $13 . \mathrm{b}$ & Tingkat Keuntungan (\%) & 67,82 & 68,76 & 71,22 \\
\hline \multicolumn{5}{|c|}{ Balas Jasa dari Faktor-Faktor Produksi } \\
\hline 14 & Marjin (Rp/Kg) & Rp. $728.000,00$ & Rp. $756.000,00$ & Rp.840.000 \\
\hline $14 . \mathrm{a}$ & Imbalan tenaga kerja (\%) & 19,6 & 18,89 & 17,60 \\
\hline $14 . \mathrm{b}$ & Sumbangan input lain (\%) & 7,71 & 7,42 & 6,68 \\
\hline $14 . \mathrm{c}$ & Keuntungan (\%) & 72,66 & 73,67 & 76,30 \\
\hline
\end{tabular}

Berdasarkan Tabel 2, rasio nilai tambah setiap entitas berbeda karena adanya perlakuan komoditas jagung yang berbeda. Rasio nilai tambah pada entitas pengumpul besar lebih besar yaitu $87 \%$ dengan nilai Rp. 783. 840,- dibandingkan dengan pengumpul kecil $(86,4 \%)$ dengan nilai Rp. 699.840,- dan petani $(86,13 \%)$ dengan nilai Rp. 671.840,-. Perlakuan bahan baku jagung pada petani rata-rata setelah dipanen dilakukan pengeringan dengan menggunakan sinar matahari. Biasanya penjemuran dilakukan sehari atau 2 hari. Jika cuacanya mendung, jagung hanya disimpan dan menunggu pengumpul kecil mengambil bahan baku. Hal ini menyebabkan kadar air komoditas jagung di tingkat petani masih tinggi yaitu di atas $14 \%$. Kondisi penanganan seperti ini sangat rentan menyebabkan kerusakan pada biji jagung dan penurunan kandungan gizinya (Widaningrum dkk., 2010).

Pengumpul kecil memberikan perlakuan berupa sortasi atau pemilahan produk yang mengalami penurunan mutu. Mutu tersebut dilihat dari segi fisik yaitu berupa ukuran dan kerusakan mekanis. Adapun kerusakan mekanis bisa berupa susut berat, memar, cacat, kotor, terdapat butiran pecah, dan perubahan warna karena mulai terjadi pembusukan (Kristanto, 2008 dalam Hasnani, 2019). Menurut Amalia dkk. (2018) kerusakan mekanis dalam rangkaian kegiatan di rantai pasok perlu diperhatikan, karena dapat menjadi titik awal bagi kerusakan-kerusakan lain seperti kimiawi dan mikrobiologi. Setelah itu beberapa pengumpul langsung mengemas komoditas jagung dengan karung dan menjual komoditas ke pengumpul besar. 
Pengumpul besar juga melakukan sortasi terlebih dahulu dengan melakukan pemilahan produk yang mutunya baik dengan produk yang mulai mengalami penurunan mutu. Hal ini dilakukan untuk mendapatkan kualitas terbaik sesuai permintaan konsumen. Jagung yang kualitasnya baik dilakukan pengeringan menggunakan mesin dryer sehingga pengeringannya tidak tergantung cuaca. Jagung yg dikeringkan berupa jagung utuh dan dan jagung pipil. Pengeringan ini dilakukan untuk menurunkan kadar air jagung sesuai dengan standar SNI yaitu 14\%. Menurut Widaningrum dkk. (2010) kadar air yang tinggi menjadi penyebab tumbuhnya jamur dan menyebabkan tingginya kerusakan pada biji jagung.

Selain nilai tambah, pada Tabel 2 terdapat tingkat keuntungan yang diperoleh setiap entitas. Keuntungan pada entitas petani yaitu sebesar $67,82 \%$, sedangkan pada pengumpul kecil keuntungan yang diperoleh sebesar $73,67 \%$. Keuntungan yang paling besar berada pada entitas pengumpul besar yaitu 76,30\%. Berdasarkan hasil keuntungan ini pemasaran yang paling baik pemasaran pengumpul besar ke konsumen karena harga jual produk relatif lebih tinggi sehingga keuntungan yang diperoleh juga lebih tinggi (Bubun dkk., 2018).

\section{KESIMPULAN}

Pemetaan rantai pasok komoditas jagung di Kabupaten Tanah Laut terdiri dari 3 (tiga) entitas yaitu petani, pengumpul kecil dan pengumpul besar. Sedangkan aliran rantai pasok yang terjadi pada pemetaan rantai pasok yaitu rantai pasok 1 yang dimulai dari petani langsung ke konsumen. Rantai pasok 2 yaitu dari petani ke pengumpul besar dan ke konsumen. Sedangkan rantai pasok 3 yaitu dimulai dari petani, pengumpul kecil, pengumpul besar dan ke konsumen. Nilai tambah yang dihasilkan dari setiap entitas rantai pasok berbeda sesuai dengan perlakuan terhadap komoditas tersebut. Rasio nilai tambah yang paling tinggi adalah pengumpul besar
(87\%), pengumpul kecil $(86,4 \%)$, dan petani $(86,13 \%)$.

\section{UCAPAN TERIMAKASIH}

Terimakasih kepada Politeknik Negeri Tanah Laut yang telah memberikan dana Penelitian Dosen Dana DIPA (PD3) Tahun 2020 dengan No. Kontrak 016/PL40.5/LT/2020.

\section{DAFTAR PUSTAKA}

Amalia, R. R., Hairiyah N, Nuryati. 2017. Pemetaan Rantai Pasok Buah Naga di Kabupaten Tanah Laut. Prosiding Seminar Nasional Riset Terapan. ISSN: 2341-5662

Amalia, R. R., Hairiyah N, Nuryati. 2018. Analisis Kerusakan Mekanis dan Umur Simpan Pada Rantai Pasok Buah Naga Di Kabupaten Tanah Laut Kalimantan Selatan. Industria: Jurnal Teknologi dan Manajemen Industri 7(2):32-41.

Arsyad M. 2018. Pengaruh pengeringan terhadap laju penurunan kadar air dan berat jagung (Zea mays L.) untuk varietas bisi 2 dan NK22. Jurnal agropolitan 5(1) : 44-52.

Bubun, Sukardi, Suparno O. 2018 . Kinerja Rantai Pasok Kedelai Di Kabupaten Grobongan. Jurnal Aplikasi Bisnis dan Manajemen 4(1): 32-42.

Firmansyah IU. 2009. Teknologi Pengeringan dan Pemipilan untuk Perbaikan Mutu Benih Jagung (Studi Kasus di Kabupaten Tanah Laut, Kalimantan Selatan). Prosiding Seminar Nasional Serealia Balai Penelitian Tanaman Serealia. ISBN: 978-979-8940-279.

Furqon C. 2015. Analisis Manajemen dan Kinerja Rantai Pasokan Agribisnis Buah Stroberi di Kabupaten 
Bandung. IMAGE Jurnal Riset Manajemen 3(2): 109-126.

Hasnani S., Jamaluddin P., Ratnawaty F. 2019. Pengaruh Teknik Penyimpanan terhadap pengendalian Aflatoksin Jagung (Zea Mays L) selama penyimpanan. Jurnal Pendidikan Teknologi Pertanian 5:S37 - S47.

Husnarti. 2017. Pedagang Pengumpul di Kabupaten Lima Puluh Kota. Jurnal Pertanian Faperta UMSB 1(1): 1-8.

Kambey S.F., Kawet L., Sumarauw J.S.B. 2016. Analisis Rantai Pasokan (Supply Chain) Kubis di Kelurahan Rurukan Kota Tomohon. Jurnal Emba, 4(5):303-408

Marimin dan Magfiroh, N. 2010. Aplikasi Teknik Pengambilan Keputusan Rantai Pasok. IPB Press. Bogor.

Marimin dan Slamet A.S., 2010. Analisis Pengambilan Keputusan Manajemen Rantai Pasok Bisnis Komoditi dan Produk Pertanian. Jurnal Pangan, 19(2): 169-188.
Noviantari K., Ali Ibrahim H., Novi R. 2015. Analisis Ratai Pasok dan Nilai Tambah Agroindustri Kopi luwak di Propinsi Lampung. Jurnal Ilmu-Ilmu Agribisnis 3(1): 10-17.

Nuryanti S., Swastika D.K.S. 2011. Peran Kelompok Tani dalam Penerapan Teknologi Pertanian. Forum Penelitian Agro ekonomi, 29(2):115-128.

Saputra I.M.G.D., Anggareni I.G.A.A.L., Dharma I.P. 2017. Pola Kemitraan Usaha Tani Kelapa Sawit Kelompok Tani Telaga Biru dengan PT. Sawindo Kencana melalui Koperasi di Kabupaten Bangka Barat Provinsi Bangka Belitung. E-Jurnal Agribisnis dan Agrowisata 6(2):249-258.

Widaningrum, Miskiyah, A.S. Somantri. 2010. Perubahan sifat fisiko-kimia jagung (Zea Mays L) pada penyimpanan dengan perlakuan karbondioksida (CO2). Jurnal Agritech 30(1): 36-45. 